
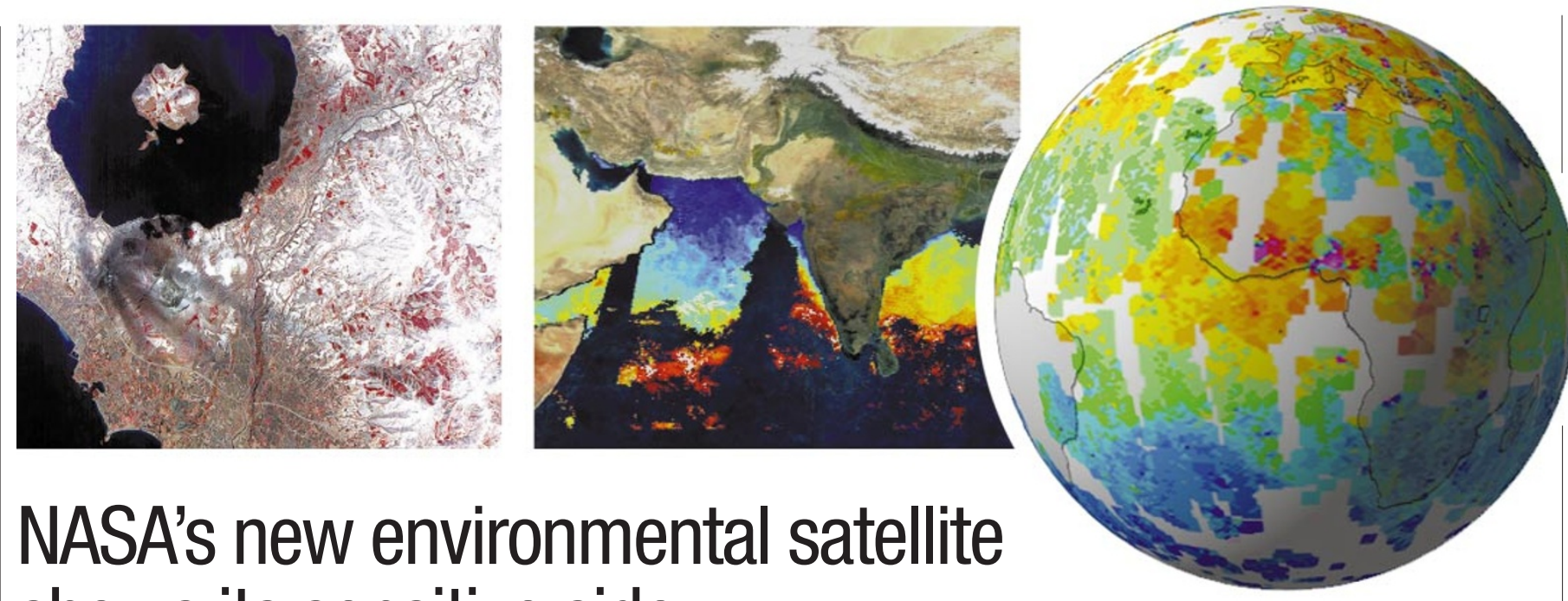

\title{
NASA's new environmental satellite shows its sensitive side
}

\section{Washington}

Beaming scientists last week showed off the first images from NASA's Terra satellite. The flagship of the \$11 billion Earth Observing System, Terra is dedicated to long-term monitoring of the home planet's surface, ocean, ice and atmosphere.

All five of Terra's instruments have checked out "in great shape" since the satellite's December launch, says NASA's head of Earth science, Ghassem Asrar. Although it is likely to take months for Terra to produce significant scientific results, the instruments are already showing their great sensitivity.

For example, the Japanese ASTER (advanced spaceborne thermal emission and reflection) instrument caught the aftermath of Mount Usu's volcanic eruption on 31 March (see top left). The three dark streaks in this visible-infrared image are ash deposits.

The US-built moderate-resolution imaging spectroradiometer (MODIS), aside from tracking vegetation changes on the land, is unique among satellite sensors in its ability to monitor the health of plankton in the ocean by measuring fluorescence (see top centre). This MODIS view over the Arabian Sea shows the highest amounts of photosynthetic activity in blue and lower ones in red.

The Canadian MOPITT (measurements of pollution in the troposphere) sensor maps atmospheric carbon monoxide at levels of one part in ten million (see top right). The red and violet areas over western Africa in this image show high carbon monoxide levels caused by seasonal fires.

Tony Reichhardt

\section{Japan gears up for growth in genomics}

Tokyo

Plans for a high-speed genome sequencing centre, announced earlier this month by biotechnology company Takara Shuzo, are widely being seen as evidence of an increased willingness by Japanese industry to invest in genomics and post-genomics research.

The new centre, which represents an investment of US $\$ 60$ million, will be located in Kusu-cho, Mie Prefecture. Called Dragon Genomics, the centre will have a sequencing capacity of about half the peak capacity of the US company Celera Genomics, making it the largest sequencing facility in Asia.

"This is the first corporate genome sequencing centre in Asia with the capacity of doing genome-size sequencing efficiently," says Makoto Moriguchi, director for sales and marketing in Takara's Biomedical Group, and business development manager of the project.

Takara Shuzo has chosen sequencing equipment developed jointly by scientists at the Research Institute for Physical and Chemical Research (RIKEN) in Tsukuba, near Tokyo, and the instrument manufacturer Shimadzu. To cut costs, sample prepa- ration will be undertaken by Takara Biotechnology, a division of Takara Shuzo in Dalian, North China. Functional analysis of the genes will be done at the company's research centre in Shiga, Japan.

According to Moriguchi, Dragon Genomics will initially offer contract sequencing services to pharmaceutical and food-processing companies both in Japan and internationally. But Takara also plans to sell sequencing data of important microorganisms, and it will seek patent protection for genes encoding useful proteins. About a fifth of the new centre's capacity will be dedicated to marine biotechnology.

"We do not intend to target the human genome, since this is not an area where we feel we can compete any more. But there are many other areas where much remains to be done," says Moriguchi.

Following a surge in public funding for genomics and post-genomics within this year's government research budget, equipment manufacturers Hitachi and Shimadzu have also announced their intention to expand contract sequencing facilities.

According to Tetsuo Ichikawa, managing officer of Shimadzu's analytical instruments division, the company plans to provide sequencing services to national research centres and universities.

But while Shimadzu sees contract sequencing services mainly as part of a strategy to sell its equipment, the electronics giant Hitachi has taken the unusual step of setting up an independent life-science group. Hiroya Taguchi, president and chief executive officer of Hitachi's Life Science Group, says the main focus of the new group, which was set up formally last September, will be on sequencing and database services for pharmaceutical companies and public organizations.

Taguchi says that Hitachi is "several years behind US and European companies" and will initially target only Japanese clients. But, he argues that the company's experience in information technology and high-performance computing means that it is well positioned to become a global player in genome informatics.

According to Moriguchi, Takara Shuzo also plans to install a high-performance computing facility at its Shiga research centre. But Moriguchi concedes that the company lacks experience in bioinformatics and is currently seeking a partner.

Robert Triendl 